\title{
Damage in woven CFRP laminates under impact loading
}

\author{
H. Ullah, A.R. Harland, and V.V. Silberschmidt \\ Wolfson School of Mechanical and Manufacturing Engineering, Loughborough University, Leicestershire, LE11 \\ 3TU, UK
}

\begin{abstract}
Carbon fibre-reinforced polymer (CFRP) composites used in sports products can be exposed to different in-service conditions such as large dynamic bending deformations caused by impact loading. Composite materials subjected to such loads demonstrate various damage modes such as matrix cracking, delamination and, ultimately, fabric fracture. Damage evolution affects both in-service properties and performance of CFRP that can deteriorate with time. These failure modes need adequate means of analysis and investigation, the major approaches being experimental characterisation and numerical simulations. This research deals with a deformation behaviour and damage in composite laminates due to dynamic bending. Experimental tests are carried out to characterise the behaviour of a woven CFRP material under large-deflection dynamic bending in impact tests carried out to obtain the force-time and absorbed energy profiles for CFRP laminates. Damage in the impacted laminates is analysed using optical microscopy. Numerical simulations are performed to study the deformation behaviour and damage in CFRP for cases of large-deflection bending based on three-dimensional finite-element models implemented in the commercial code Abaqus/Explicit. Multiple layers of bilinear cohesive-zone elements are employed to model the initiation and progression of inter-ply delamination observed in the microscopy studies. The obtained results of simulations show good agreement with experimental data.
\end{abstract}

\section{Introduction}

Fibre-reinforced composites such as carbon fibre-reinforced polymers (CFRP) are widely used in aerospace, automotive and construction structures due to their high specific strength and stiffness. Woven-fabric composite laminates offer a number of attractive mechanical properties compared to their unidirectional-tape counterparts such as good resistance to fracture and transverse rupture due to weaving resistance, and high impact strength [1]. These properties have attracted the sports industry to incorporate woven CFRP laminates in the design of sports products that could be subjected to large-deflection bending and multiple impacts in service conditions. This type of quasistatic and dynamic loads generate high local stresses and strains leading to complex damage modes due to heterogeneity and anisotropy of composite laminates. Composite structures suffer more damage as a result of impact than equivalent metallic structures. The damage mechanisms typically caused by out-of-plane impact loads are matrix cracking, fibre breakage and delamination at interfaces within the composite structure [2]. Impact damage and, in particular, delamination occurring at low-velocity impact causes a significant decrease in the material's in-plane compressive strength and stiffness. Such internal damage mechanisms that often cannot be detected by visual inspection degrade the load bearing capacity of the structures. Therefore, it is very important to study the damage suffered by the composites under impact loading conditions.

Woven composites have been widely used in impactprone structures as they offer better resistance to impact damage than unidirectional (UD) tape laminates due to their interlacing (weaving) tow architecture limiting the damage growth between layers [3]. Furthermore, the transverse tensile strength of the woven composites is much higher than the UD composites, which is one of the possible reasons for the superior impact resistance characteristics of woven composites [4]. Woven composites provide balanced in-plane mechanical properties and are characterised by high fracture toughness and ease of handling and formability. Woven composites can also be tailored to specific applications by employing different weave patterns and even different tow materials in case of hybrid composites to give appropriate levels of stiffness and impact strength in desired directions. These properties, especially high work of fracture and impact resistance, have provided many opportunities for woven composites in applications demanding exceptional damage tolerance. However, woven laminates exhibit a fibre breakage failure mode more commonly than UD laminates because fibres are interlaced with each other resulting in high degree of fibre crimp or waviness at cross-over points inducing stress concentrations. Besides, planar 2D woven laminates consist of continuous fibres that result in lower in-plane mechanical properties due to fibre crimping [5].

The low-velocity impact response of woven-fabric composite laminates has been extensively treated in the literature by experimental research works, analytical formulations and numerical implementations. Abrate [6] analysed dynamics of impacts using an analytical approach based on energy-balance and spring-mass models. Naik et al. [4] studied the behaviour of woven-fabric composite plates under transverse low-velocity impact employing an analytical model based on a modified Hertz law and a 3D numerical model. Johnson et al. [7] presented a materials failure model for composites with fabric reinforcement under impact loading, which included both intra-ply damage and plasticity based on continuum damage mechanics approach, and inter-ply delamination. Iannucci and Willows [8] presented an energy-based damage mechanics model and interface modelling technique for woven carbon composites under high strain dynamic loading employing 
an explicit FE code. Reyes and Sharma [5] studied experimentally and numerically a low-velocity impact damage behaviour of woven GFRP laminates under various levels of impact energies. However, majority of these studies are dedicated to the impact behaviour of composites tested with instrumented dropping weight impact towers, which usually caused localised damage such as penetration and perforation in impacted laminates. A large-deflection dynamic bending behaviour of composites laminates caused by a pendulum-type impactor is rarely investigated. Although such an instrumented impactor has been used by Silberschmidt et al. [9] and Casas-Rodriguez J P et al. [10] to study damage in adhesively bonded CFRP joints under repeated impacts, the loading mode there was tensile. In this connection, the authors studied earlier the largedeflection behaviour of woven laminates under quasi-static bending and tensile loads [11-13]. In the present work, a large-deflection bending behaviour of woven-fabric CFRP laminates subjected to impact loads is studied. Flexural impact tests were carried out using a pendulum type impact tester at various energy levels. The type and location of damage were investigated with optical microscopy. A multi-body-dynamics impact finite-element model was developed in Abaqus/Explicit for both undamaged and damaged specimens. In the present work only the results of undamaged FE model are presented as the damage-model solution is still running. The obtained model results have good agreement with our experimental data.

\section{Experimental methods}

\subsection{Specimen preparation}

The materials studied were laminates of woven fabric made of carbon fibres reinforcing a thermoplastic polyurethane (TPU) polymer matrix. The fabric was produced from $0^{\circ} / 90^{\circ}$ prepregs in the form of four plies designated as $\left[0^{\circ}, 90^{\circ}\right]_{2 s}$, where $0^{\circ}$ and $90^{\circ}$ represent yarns in the warp and weft directions, respectively. The woven laminate had $2 / 2$ twill weaving pattern with a fibre volume fraction of $45 \%$; the fabric had the same number of yarns in the warp and weft directions. Un-notched rectangular specimens of $40 \mathrm{~mm}$ length, $25 \mathrm{~mm}$ width and $1.0 \mathrm{~mm}$ thickness were prepared; each laminate having four layers of $0.25 \mathrm{~mm}$ thickness. Before dynamic testing, both side edges of the specimens were polished to a scratch-free surface finish with the aid of $3 \mu \mathrm{m}$ and $1 \mu \mathrm{m}$ diamond spray on DUR cloths.

\subsection{Experimental procedure}

Dynamic impact tests were carried out on an instrumented pendulum type CEAST Resil impactor according to ISO 180 standard. In the impact tests, the bottom of the specimen was fixed firmly in the machine vice as a cantilever beam. The upper $30 \mathrm{~mm}$ of the specimen was struck by the striking nose of the pendulum hammer with a controlled level of energy, resulting in dynamic largedeflection bending. The distance between the fixed support

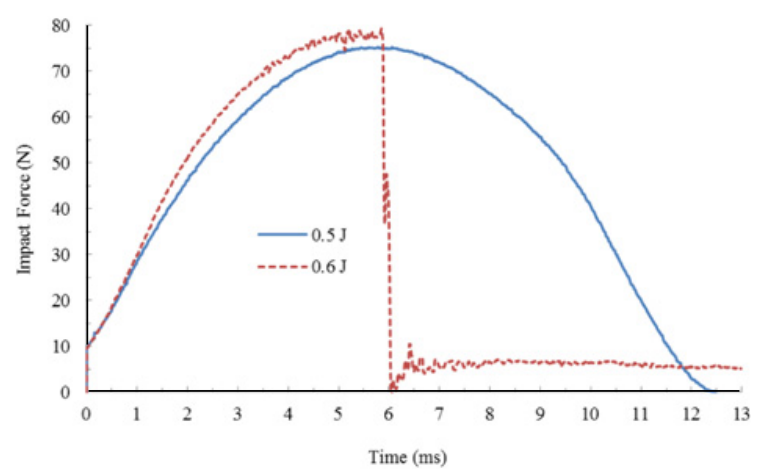

Fig. 1. Force-time response of twill $2 / 2$ woven CFRP laminate in impact test.

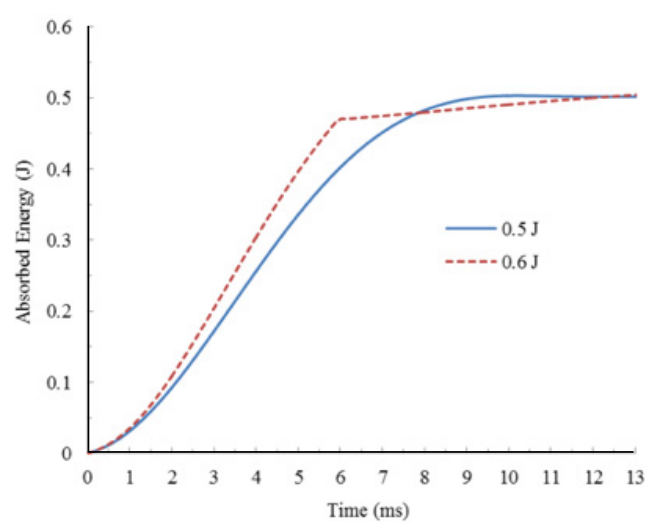

Fig. 2. Energy-time response of twill 2/2 woven CFRP laminate in impact test.

and the line of contact of the hammer's striking nose was kept $22 \mathrm{~mm}$ according to the standard. In this work, a calibrated impact hammer with a mass of $0.6746 \mathrm{~kg}$ and $0.3268 \mathrm{~m}$ length was used. The hammer can generate an impact of maximum energy of $2 \mathrm{~J}$ at impact velocity of $3.46 \mathrm{~m} / \mathrm{s}$ corresponding to the initial angle of $150^{\circ}$ to the striking position. The magnitude of initial impact energy and velocity can be varied by changing the initial angle of the hammer. CFRP specimens were tested at various energy levels to determine the energy inducing the ultimate fracture of the specimen. It was found that the specimen fractured at $0.6 \mathrm{~J}$ corresponding to the initial angle of $64^{\circ}$. The rest of the tests were carried at $0.5 \mathrm{~J}$ corresponding to $58^{\circ}$ to study the behaviour of sub-critical damage modes such as matrix cracking and delamination. A piezoelectric force transducer was fixed rigidly to the hammer striking nose to capture the impact force signal. The pendulum hammer is released from the pre-defined initial angle. The impact with the specimen generates a change in electrical resistance of the piezoelectric sensor that is captured by the data - acquisition system - DAS 8000 - connected to the Resil impactor. The signal is registered with a predefined sampling frequency of $833 \mathrm{kHz}$, with up to 8000 data points recorded per impact test. In order to decrease the data noise a $1 \mathrm{kHz}$ filter was used. Typical records of force vs. time for un-fractured and fractured CFRP specimens are presented in Figure 1. Similarly, evolution of the specimen absorbed energy is shown in Figure 2. 

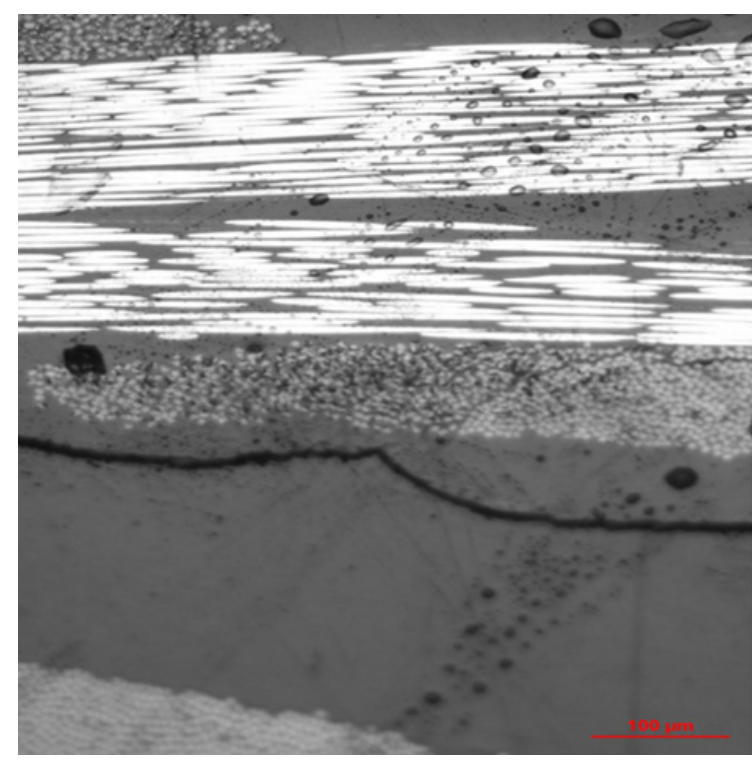

Fig. 3. Inter-ply delamination in CFRP laminate.

Although the un-fractured samples underwent interlaminar damage before the structure lost its load carrying capacity, the development of such inter-ply delamination was not reflected in the force-time plot for $0.5 \mathrm{~J}$ in Figure 1.

\subsection{Microscopic analysis}

Microscopic analysis of the composite specimens is a suitable technique for evaluation of damage in wovenfabric laminates. In order to visualize the type and location of damage, microscopic analysis allows for the study of the comprehensive damage behaviour of the composite specimen. This technique was also employed in [14] for damage characterisation of woven CFRP laminates. In this work, OLYMPUS BX-60M microscope was used to capture the images of the through-thickness side edge of the un-fractured specimen to observe the barely visible damage on the specimen surface. Image-Pro Plus software was used for the analysis of the microscopic images that were captured.

Interlaminar damage developed in the large-deflection dynamic bending is presented in micrograph of Figure 3. The main mode of damage is delamination along the specimen's longitudinal axis that was expected due to high in-plane shear stresses. At this stage of loading, weft yarn cracking (intra-ply delamination) and transverse matrix cracking can also be observed in the micrograph shown in Figure 4. Here, it can be observed that damage initiation occurred at the weft yarn edge (crimp location) and then propagated into the weft yarn as well as inter-ply transverse matrix cracking. Interaction of Intra-ply weft yarn cracking and inter-ply transverse matrix cracking also occurred (Figure 4). Intra-ply delamination in the weft yarn can be clearly seen in the microscopic image of Figure 5. Some of these damage modes, e. g. delamination, will be incorporated in our FE models.

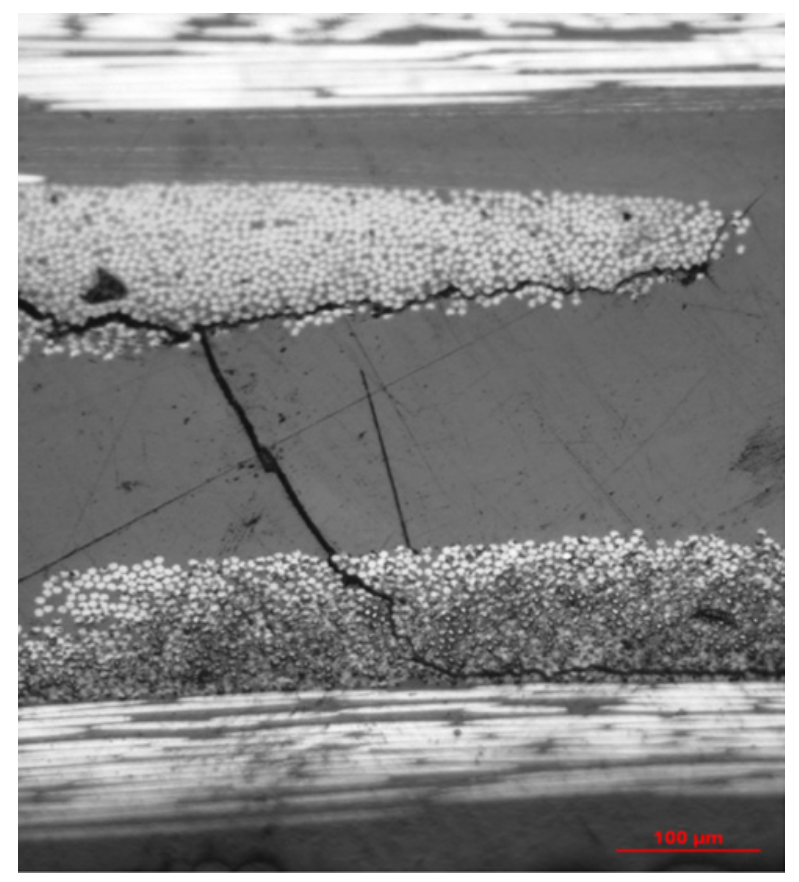

Fig. 4. Intra-ply tow delamination in weft yarn and transverse matrix cracking in CFRP laminate.

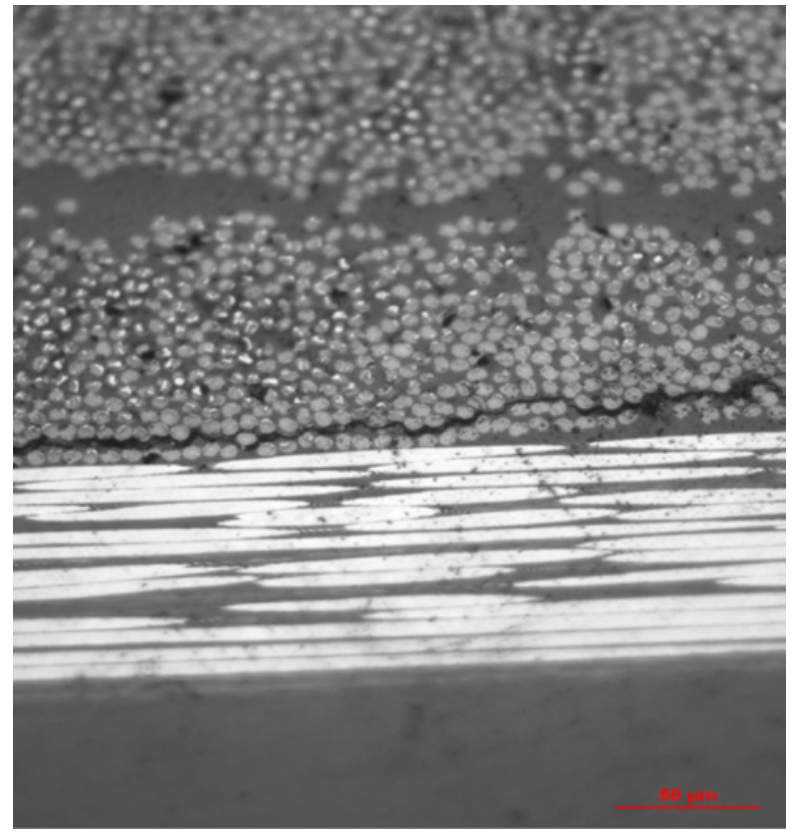

Fig. 5. Intra-ply delamination in weft tow in CFRP laminate.

\section{Finite-element modelling}

\subsection{Modelling strategy}

Finite-element models were developed in the commercial FE package ABAQUS/Explicit to investigate largedeflection dynamic bending of tested composite laminates and the resulting inter-ply damage. Two FE models - Models A and B were developed representing the impact tests on, respectively, un-fractured and fractured $40 \mathrm{~mm}$ long, $25 \mathrm{~mm}$ wide and $1 \mathrm{~mm}$ thick CFRP laminates. Geometry 
Table 1. Material properties of CFRP considered in FE model.

\begin{tabular}{lllr}
\hline Elastic properties & & Interlaminar strength and toughness \\
\hline $\mathrm{E}_{11}=\mathrm{E}_{22}(\mathrm{GPa})$ & 44.7 & $\sigma_{\mathrm{I} 0}(\mathrm{MPa})$ & 12 \\
$\mathrm{G}_{12}(\mathrm{GPa})$ & 4.4 & $\sigma_{\mathrm{II}}(\mathrm{MPa})$ & 26 \\
$v_{12}$ & 0.05 & $\mathrm{G}_{\mathrm{Ic}}\left(\mathrm{J} / \mathrm{m}^{2}\right)$ & 800 \\
$\mathrm{E}_{33}(\mathrm{GPa})$ & 8.0 & $\mathrm{G}_{\mathrm{IIc}}\left(\mathrm{J} / \mathrm{m}^{2}\right)$ & 1750 \\
$\mathrm{G}_{13}=\mathrm{G}_{23}(\mathrm{GPa})$ & 3.0 & & \\
$\mathrm{v}_{13}=\mathrm{v}_{23}$ & 0.3 & & \\
\hline
\end{tabular}

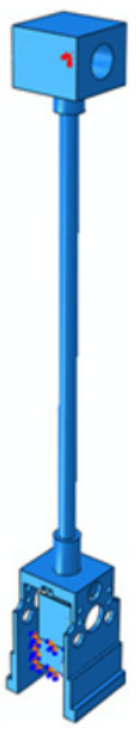

(a)

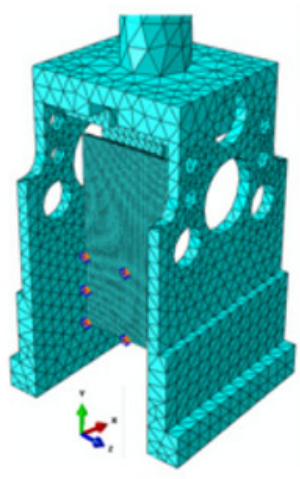

(b)

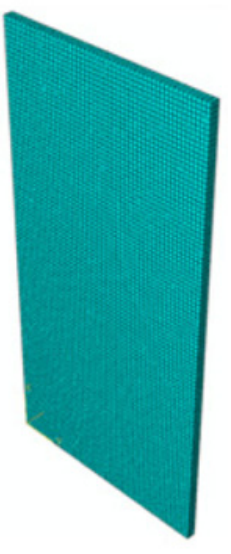

(c)
Fig. 6. Impact test model (a); hammer-specimen contact interaction (b); mesh of specimen (c).

along with mesh and boundary conditions of Model A is shown in Figure 6. This model is developed first to validate the dynamic contact behaviour of the hammer and specimen without incorporating any damage. The hammer was discretised with 4-noded linear tetrahedron C3D4 elements, whereas the specimen was meshed with 8-noded linear brick C3D8R elements using a structured meshing technique. These reduced-integration elements are capable of controlling hourglass and eliminating shear locking in bending-dominated problems. Each ply of the laminate was modeled with a single element through its thickness. In Model-B, cohesive zones elements were introduced at the interface between laminate's plies based on delamination observed in the microscopy of the specimen. Three layers were inserted between coincident nodes at the ply interfaces of the studied laminate. Elastic as well as damage properties of interlaminar cohesive layers presented in Table 1 can be found in the previous work of the authors [12]. The surface-to-surface kinematic contact algorithm with finite sliding available in ABAQUS/Explicit was used to simulate contact between the rigid hammer's striking nose and the laminate's surface. The rigid impactor striking and specimen surfaces were defined as master and slave surfaces, respectively, in the model.

\subsection{Interlaminar damage modelling}

Cohesive-zone elements (CZE) have the ability to capture the onset and propagation of delamination $[11,15,16]$. The cohesive behaviour assumes that failure of elements is characterized by progressive degradation of the material stiffness, which is driven by a damage process. Interlaminar damage modes in composite laminates initiate and propagate under the combined influence of normal and shear stresses. The nominal quadratic stress criterion is used for damage initiation. Damage propagation is usually predicted by criteria established in terms of the energy release rates and fracture toughness under mixed-mode loading. This study is based on the criterion proposed by Benzeggah and Kenane [17]:

$$
G_{e}=G_{I \mathrm{c}}+\left(G_{I I \mathrm{c}}-G_{I \mathrm{c}}\right)\left[\frac{G_{\mathrm{s}}}{G_{\mathrm{r}}}\right]
$$

where $G_{\mathrm{T}}$ is the work by the interface tractions; $G_{\mathrm{s}} / G_{\mathrm{T}}$ is the fraction of cohesive energy dissipated by shear tractions; $G_{\mathrm{s}}$ is the work done by the shear components of interface tractions; $G_{I \mathrm{c}}$ and $G_{I I c}$ are critical energy release rates in modes I and II, respectively, and $\eta$ is the material mode-mixity parameter. The damage initiation and fracture toughness parameters presented in Table 1 were used in FE Model B. The interface element stiffness was based on the approach by Daudeville et al.. [18], which defined the interface stiffness as $K=E_{33} / t_{i}$, where $E_{33}$ is the material's through-thickness stiffness and $t_{i}$ is the thickness of the resin-rich interface between plies. Based on this relation, the value of interface stiffness of $4 \times 10^{6} \mathrm{~N} / \mathrm{mm}^{3}$ is used in this study assuming interface thickness of $2 \mu \mathrm{m}$. The application of CZE requires a fine spatial discretization at the cohesive zone to capture the damage growth properly. The number of elements $N_{e}$ in the cohesive-zone is determined according to $N_{e}=$ $l_{c z} / l_{e}$, given in [15], where $l_{c z}$ is the length of cohesivezone and $l_{e}$ is the mesh size in the direction of crack propagation. Cohesive elements of size $0.3 \mathrm{~mm} \times 0.3 \mathrm{~mm}$ with thickness of $2 \mu \mathrm{m}$ were defined for computationally effective simulations of damage in numerical Model B.

\subsection{Boundary conditions and solution}

A node at the pivot point of the hammer along the axis of rotation was created and then tied with hammer cylindrical pivot surface through tie constraints. All translations and rotations of the pivot node were constrained except rotation about $\mathrm{z}$-axis to simulate the hammer's centre of rotation. In the FE models, initial position of the hammer's striking nose was just in contact with the specimen to avoid the computational cost of bringing the hammer from the initial angle of $58^{\circ}$. An initial angular velocity of $5.33 \mathrm{rad} / \mathrm{s}$ was applied to the whole hammer corresponding to the initial angle modelled. All the degrees of freedom of the specimen's bottom were constrained to replicate its boundary conditions in the vice.

Dynamic analysis was performed with an Abaqus/ Explicit solver, which is more efficient than an implicit solver, especially for highly nonlinear problems involving contact and large deformations. The load was applied gradually in small time increments of $10^{-8} \mathrm{~s}$ using automatic time stepping to capture the dynamic largedeflection bending process. Model A without damage 
contained a total of 28,703 elements with 74,474 DOFs, and it took $2 \mathrm{~h}$ on a six-core machine with two $3.33 \mathrm{GHz}$ processors each to run the simulations. Similarly, the damage Model B had a total of 48,703 elements with 136,286 DOFs, and simulations with it have not been accomplished yet. The computational cost is a direct consequence of a fine mesh coupled with the highly nonlinear behaviour of interface damage elements.

\section{Discussion of results}

Results of experimental tests and numerical simulations for the large-deflection dynamic bending behaviour of woven CFRP laminates are presented in this section. CFRP specimens were subjected to impact energies of $0.5 \mathrm{~J}$ and $0.6 \mathrm{~J}$ using an instrumented pendulum impact hammer. Figure 1 shows the variation of load with time for both energy levels. At the energy level of $0.5 \mathrm{~J}$, the loading and unloading curve has a symmetrical parabolic shape suggesting that the respective stages during the contact duration are almost the same and no significant damage has occurred. The impact force at $0.6 \mathrm{~J}$ energy, causing the specimen's ultimate fracture, is higher. Here, a higher impact energy induces larger deformation and therefore, larger impact force. The load vs. time graph in Figure 1 shows oscillations due to significant damage inside the specimen before its ultimate bending fracture. The ultimate fabric fracture is represented by the sudden drop in contact force implying a momentary loss of contact between the impactor and specimen. Figure 2 shows the variation of specimen's absorbed energy with time. The amount of energy transferred from the impactor to composite specimen at the end of impact events, i.e. absorbed energy, increases with the impact energy since a higher impact energy results in a more severe damage to a composite specimen. As shown in Figure 2, the absorbed energy increases with time during loading, reaches a maximum value and then decreases during unloading, and finally remains horizontal, i.e. reaches a constant value for $0.5 \mathrm{~J}$ impact energy. Whereas for $0.6 \mathrm{~J}$, the absorbed energy reaches a value of $0.48 \mathrm{~J}$ at $6 \mathrm{~ms}$ and then gradually increases. The stabilized energy level indicates that the impactor has lost contact with the specimen. This constant value gives the total energy absorbed permanently by composite specimens at the end of an impact event.

The load vs. time response of our numerical ModelA is compared with experimental curve of un-fractured specimen in Figure 7. The load peak of the FE model is higher than the experimental one. This discrepancy may be due to the fact that the FE model did not take into account the real physical energy losses due to material viscous damping and friction between the interacting parts of the experimental setup. However, the contact duration is almost the same implying that the stiffness of the impacted specimen was accurately modelled. Variation of kinetic (impact) and strain (absorbed) energy with time for the whole FE model is presented in Figure 8. As it is evident, at the start of impact event, kinetic energy is maximum and the strain energy is minimum. Gradually, the kinetic energy is imparted to the specimen and its strain energy increases. As no damage is incorporated in Model-A, so no energy loss can be observed in Figure 8.

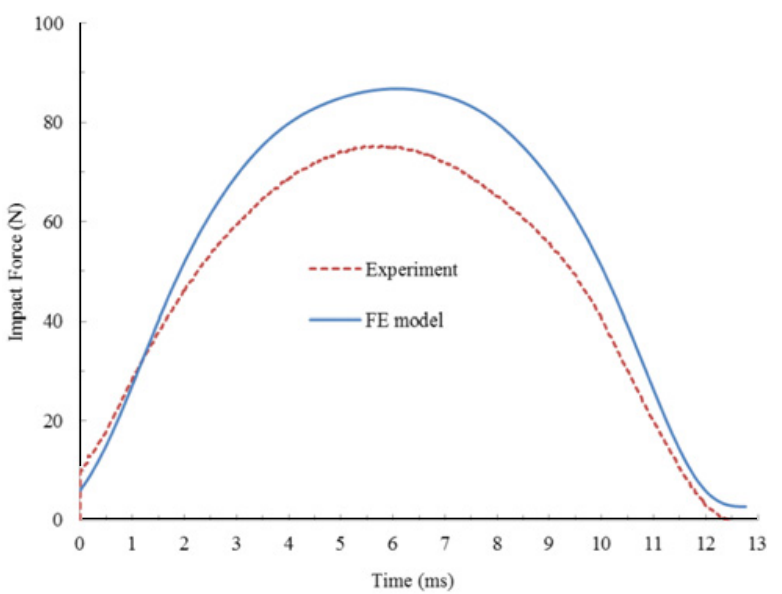

Fig. 7. Comparison of experimental and numerical results in terms of force-time response of CFRP laminates.

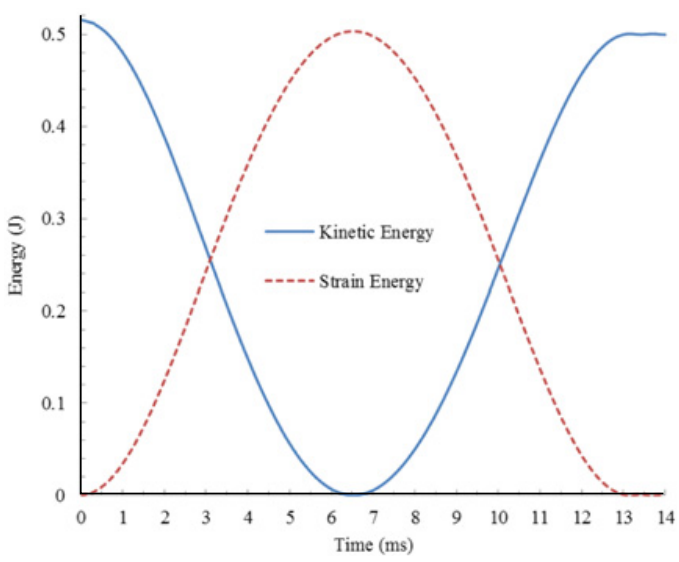

Fig. 8. Variation of kinetic (impact) and strain (absorbed) energy with time for CFRP laminate.

\section{Conclusions}

The dynamic behaviour of woven CFRP laminates under large-deflection bending was studied using experimental tests and numerical simulations. Impact tests were carried to characterise the material's dynamic behaviour. Experimental results highlighted the energy absorbing capabilities of the CFRP composites. Microscopic analysis was carried out to observe different damage modes in the impacted specimens. This analysis forms a basis for damage modelling of the composite laminates in future models. Numerical models helped to gain a better understanding of the multi-body impact dynamics. The numerical results were in agreement with experimental data and thus validated the modelling approach of the dynamic event. Results of the damage model are not presented as the numerical solution of the model is still running because of a large number of DOFs of the model.

\section{References}

1. G. Ernst, M. Vogler, C. Hühne, and R. Rolfes, Composites Science and Technology 70 (1), 61 (2010).

2. C. Menna, D. Asprone, G. Caprino, V. Lopresto, and A. Prota, International Journal of Impact Engineering 38 (8-9), 677 (2011). 
3. M. P. F. Sutcliffe, C. Monroy Aceves, W. J . Stronge, R. S. Choudhry, and A. E. Scott, Composite Structures doi: 10.1016/j.compstruct. 2011.12.026 (2012).

4. N. K. Naik, Y. Chandra Sekher, and S. Meduri, Composites Science and Technology 60 (5), 731 (2000).

5. G. Reyes and U. Sharma, Composite Structures 92 (2), 523 (2010).

6. S. Abrate, Composite Structures 51 (2), 129 (2001).

7. A. Johnson, A. Pickett, and P. Rozycki, Composites Science and Technology 61 (15), 2183 (2001).

8. L. Iannucci and M. Willows, Composites Part A: Applied Science and Manufacturing 37 (11), 2041 (2006).

9. V. V. Silberschmidt, J . P. Casas-Rodriguez, and I. A. Ashcroft, Key Engineering Materials 399, 671 (2009).

10. J. Casas-Rodriguez, I. A. Ashcroft, and V. V. Silberschmidt, Composites Science and Technology 68 (13), 2663 (2008).
11. H. Ullah, A. R. Harland, T. Lucas, D. Price, and V. V. Silberschmidt, Computational Materials Science 52 (1), 147 (2012).

12. H. Ullah, A. R. Harland, T. Lucas, D. Price, and V. V. Silberschmidt, J ournal of Physics: Conference Series 305, 12045 (2011).

13. H. Ullah, A. R. Harland, R. Blenkinsopp, T. Lucas, D. Price, and V. V. Silberschmidt, Applied Mechanics and Materials 70, 363 (2011).

14. S. Daggumati, E. Voet, W. Van Paepegem, J. Degrieck, J . Xu, S. V. Lomov, and I. Verpoest, Composites Science and Technology 70, 1926 (2010).

15. A. Turon, C. G. Davila, P. P. Camanho, and J . Costa, Engineering Fracture Mechanics 74 (10), 1665 (2007).

16. H. Ullah, A. R. Harland, and V. V. Silberschmidt, Applied Composite Materials doi: 10.1007/s10443011-9242-7 (2011).

17. M. L. Benzeggagh and M. Kenane, Composites Science and Technology 56 (4), 439 (1996).

18. L. Daudeville, O. Allix, and P. Ladeveze, Composites Engineering 5 (1), 17 (1995). 